\title{
CORRIGENDUM
}

\section{The human involucrin gene contains spatially distinct regulatory elements that regulate expression during early versus late epidermal differentiation}

James F Crish, Frederic Bone, Eric B Banks and Richard L Eckert

DOI: $10.1038 / \mathrm{sj} /$ onc/1205456

Correction to: Oncogene (2002) 21, 738-747. DOI: $10.1038 / \mathrm{sj} / \mathrm{onc} / 1205038$

The authors wish to apologise that Figure $4 \mathrm{a}$ of the above manuscript was submitted in black and white. The figure is reproduced in colour below:
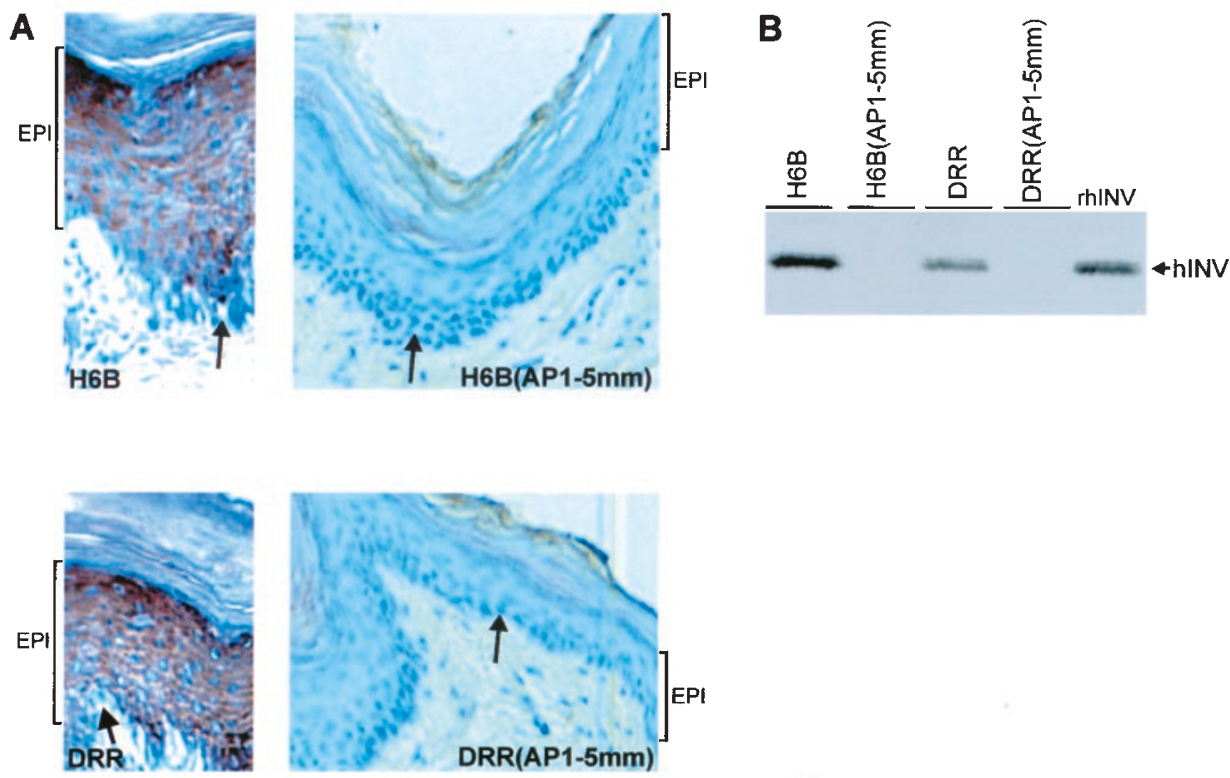